\title{
The Influence of Turkish Drama on Socio-Cultural Values of Saudi Women
}

\author{
Merfat Alardawi ${ }^{1}$, Ayman Bajnaid ${ }^{2} \&$ Pat Brereton $^{3}$ \\ ${ }^{1}$ Department of Audio-visual Production, King Abdul-Aziz University, Jeddah, Saudi Arabia \\ ${ }^{2}$ Department of Digital Media and Journalism, King Abdul-Aziz University, Jeddah, Saudi Arabia \\ ${ }^{3}$ School of Communications, Dublin City University, Dublin, Ireland \\ Correspondence: Merfat Alardawi, Department of Audio-visual Production, King Abdul-Aziz University, Jeddah, \\ Saudi Arabia.
}

Received: June 1, 2021

Accepted: June 21, 2021

Online Published: July 7, 2021

doi:10.5539/mas.v15n4p47

URL: https://doi.org/10.5539/mas.v15n4p47

\begin{abstract}
Dramas made in Turkey are the most popular soap opera-type in the Arab world and are often watched by women. This study aimed to investigate, from a critical perspective, the impact that Turkish dramas (TDs) might have on developing attitudes of Saudi women. While more than 60 country-specific studies in the Middle East and North Africa have investigated the impact of dramas on audiences, Research regarding Saudi Arabia is surprisingly lacking. Therefore, the effect of TDs on Saudi women was examined as part of this study. Qualitative methodology was used, and semi-structured interviews were conducted with eight Saudi women (aged between 18 and 40) who have watched TDs. Following the groupings, qualitative analysis techniques were employed as part of thematic analysis (TA). The responses of Saudi women highlighted the different types of impacts that TDs have on Saudi audiences: positive, negative, and neutral. The study made a small but essential contribution to an under-researched issue of pleasures of TDs and their representational heuristics in capturing both positive, negative, and so much in between for a particular cohort of Saudi women. It is the first qualitative examination of the impact of TDs on Saudi women's attitudes.
\end{abstract}

Keywords: Turkish drama, social and cultural values, Saudi women, attitudes, soap opera, ethical issues

\section{Introduction}

Since the 2000s, Turkish Dramas (TDs) have played a diverse and significant role in many cultures, especially those in the Arab world (Berg, 2017; Bhutto, 2019; Toul, 2020). Hence, many scholars have defined TDs as being an irregular phenomenon and a form of soft power (Aljammazi \& Asli, 2017). The study is likely to make a small but essential contribution to an under-researched issue of TDs and their representational heuristics in capturing both positive, negative, and so much in between, for a particular cohort of Saudi women. Georgiou, (2012) conducted a study on trinational Arabic television; soap operas and their viewing among women in Arab diaspora. The study found that significant role is played by soap operas in supporting a gendered critical and reflexive closeness to the Arab world. The study also found that the Arab women in diaspora viewing opera soaps provided them with opportunities to reflect on their identities as different from the hegemonic discourses of gender in their country of origin but close to a moral set of values they link with the same region. This was not exclusively in the case of young women born in diaspora.

It is the first qualitative examination of the impact of TDs on Saudi women's attitudes. The paper is structured as follows; the section after the introduction represents the literature review about the topic of concern tracked by methodology explaining the procedures adopted in this study. The following section presents the study results, followed by a discussion comparing and contrasting the present study results with previous studies. Implications and conclusions follow the discussion.

\section{Literature Review}

While TDs have successfully covered different themes and genres, such as family, comedy, fiction, non-fiction, and history, a great emphasis has been put on the genre of romance (Cipan, 2014). As a result, TDs have been presented to general audiences and have, in particular, appealed to women. One key point to consider was the potential adverse effects of foreign dramas on the social values of the viewers, such as honesty, the role of violence, 
and obeying one's partner (Al-Masry, 2013). In terms of religion and morality, research has consistently found that TDs present representations of moral corruption, marital Infidelity, drinking alcohol, and forbidden relationships, as being negative (Homed, 2017; Zhag \& Sakry, 2019).

Other studies have found that TDs have a more positive impact on audiences' attitudes (Hamasaee, 2018; Megdad, 2015; Yanardagoglu \& Karam, 2013). In addition, TDs are often presented in a positive light in terms of the satisfaction audiences gain from accessing new knowledge and information; the sense of excitement and social gratification involved; the portrayals of emotions, aesthetics, and recreation; the attractiveness of actors; and the vicarious ability of TDs to allow people to escape from reality (Makki \& Al-Ali, 2018; Salih, 2017; Alsaffar, 2012; Temraz, 2016).

A study conducted by Shahbaz (2015) about impact of Turkish dramas on Pakistani women found that these drams seem to gain popularity in the country in a very short span of time and attracted a huge viewership especially women. They investigated the socio-ethical effect of Turkish drams on educated females of Gujranwala as there has been a rapid penetration of them in the Pakistani society. The study conducted a survey which consisted of 20 females residing in five different areas of Gujranwala, Pakistan. The study results showed that Turkish dramas were very popular and were regarded as a source of entertainment especially among women. They thought of them as a good source of pass time. The study found that the respondent regarded socio-ethical concerns as not a part of their culture and regarded them as non- threating for their country.

Overall, most literature regarding the consumption of TDs in the Arab world and Islamic countries presents either negative or positive impacts, while some studies examined both (Yanardagoglu \& Karam, 2013). However, minimal studies investigated these three types of effects of TDs on women's attitudes. The present study fills this gap by conducting qualitative thematic analysis (TA) to examine the impact of TDs on Saudi women's perspectives in terms of positive, negative, and neutral effects. Moreover, there remains a vast gap within the research literature concerning Saudi women and their consumption of TDs. None of the previous studies have examined the influence of TDs on Saudi women's values. As a result, this study fills this gap from a critical perspective. As not much literature work has been done in this area therefore, this study also contributes to the existing body of knowledge.

\section{Methodology}

\subsection{Study Sample and Size}

Data was collected qualitatively through face-to-face interviews in the middle of October (2019) with Saudi women who have watched TDs. In terms of demographics, four people in the sample were aged between 18 and 21, and two of the participants were older than 41. The remaining participants were divided into two age groups: 22 to 30 years old and 31 to 40 years old. Concerning Muslim religion, six participants were moderately religious, while two participants were deemed religious to a minor extent.

\section{Thematic Analysis}

Following the groupings, qualitative analysis techniques were employed as part of thematic analysis (TA). This was designed to obtain answers to a predetermined research question; what is the impact of Turkish drama on Saudi women's attitudes? TA has been defined as 'A method for identifying, analysing, and reporting patterns (themes) within data' (Braun \& Clarke, 2006: 6). Regarding the application of TA, the current research used a manual process, based on Braun and Clarke's (2006) method, which consisted of six phases: (1) familiarisation with the data; (2) the creation and labeling of initial codes; (3) the development of codes into themes; (4) the revision of themes to ensure that they are related to the research questions; (5) the identification of themes by naming and defining them; and (6) writing the final report and presenting all the developed themes. In the current research, the responses of Saudi women highlighted the different types of impacts that TDs have on Saudi audiences: positive, negative, and neutral.

\section{Findings of the Study}

\subsection{Positive Impacts}

Some Saudi participants said that TDs, in general, have a positive impact on audiences. This finding is supported by other studies (Megdad, 2015; Raza \& Rehan, 2015; William, 2013). The positive effect can be separated into three main themes, which all emerged from the thematic content analysis of the interviews. Figure 1 summarises the positive themes and main concerns that were identified through interviews with female Saudi participants. A description of 27 related attributes is included. 


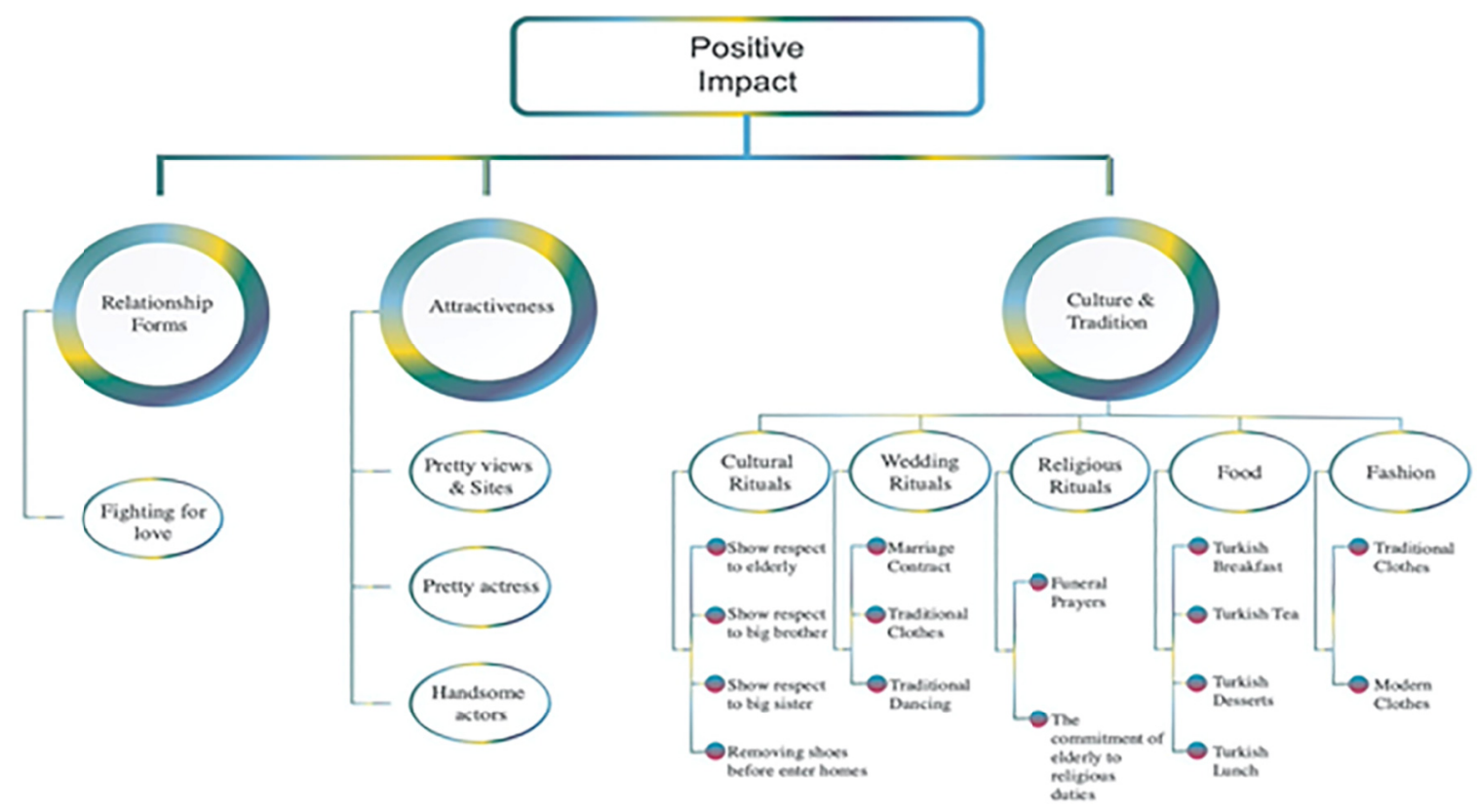

Figure 1. Positive impacts, based on responses from female Saudi participants

\subsubsection{Forms of Relationships}

The responses of some Saudi women who watched TDs highlighted that the form of a relationship and its depiction encouraged various forms of active engagement in TDs. To be precise, relationships between women and men, which are related to romantic feelings, such as passion, and other positive emotions, serve as the driving force behind the consumption of TDs. This is in line with findings from previous studies (Algan, 2005; Anaz, 2014; Güneş, 2016). When the participants were asked about the fundamental or primary emotion that they felt when watching the dramas, one participant (P3), aged 31, said,

When I watch Turkish drama, I am very optimistic and happy because of the enormous love shown in relationships between couples and husbands and wives. It is so romantic. This response falls into one of the principal sub-themes: fighting for love.

\subsubsection{Fighting for Love}

This sub-theme was shown to stimulate positive feelings, or intangible elements, ascribed by the Saudi women who watched TDs. Many participants may admire TDs simply because, in various ways, they provide a positive image of Turkish men. For instance, a male actor, or the character he plays, is ready to sacrifice love and put himself in risky situations. The Turkish man also often tries to compete with other men for love. From the perspective of the Saudi participants, a Turkish man represents someone who fights for love. Such a character is admirable in Saudi society, as most Saudi dramas are limited to portraying the difficult journeys of male protagonists finding true love. This highlights the restrictive socio-cultural norms of the country, where the expression of love is described as following the country's (restrictive) cultural norms, despite marital relationships featuring in storylines. TDs, in comparison to Saudi media content, are more open and critical: they show the problematic side of a protagonist's journey when finding love. This result in gaining a bigger fan following amongst Saudi women.

\subsubsection{Attractiveness}

According to the participants, attractiveness was the primary theme and a positive attribute of TDs. Participants highlighted pretty views and natural scenic features as well as beautiful actresses and handsome actors. The pleasant natural scenery of Turkey can attract large audiences. It also appears to be a feature that makes Turkey a favorite destination for tourists hailing from various countries, especially those coming from the Arab region (Balli et al., 2013; Corbaci \& Cetinsoz, 2008; Ozcan \& Anaz, 2016). All the interviewees liked to watch Turkish drama because of the positive feelings they promoted. 
For instance, P1, aged 51, said, Everything in TDs is very beautiful; even the homes that are not luxurious that include standard features are surrounded by natural beauty. ... I think Turkey combines Eastern and Western perspectives; it is one of the unique features of that country.

Regarding actors, most participants appeared to believe that Turkish actors were quite handsome and that the actresses were beautiful.

According to P4, aged 21, All of the heroes shown in Turkish dramas are handsome and perfect.

Several studies confirm that beautiful and visually appealing actors and actresses are crucial in engagement with most Turkish soaps (Durmus, 2016; Soheli, 2011; Talha, 2018).

\subsection{Culture and Tradition}

Saudi women's responses concerning culture and tradition highlighted a wide range of areas for discussion. These topics were placed into five main categories: cultural rituals, wedding rituals, religious rituals, food, and fashion.

\subsubsection{Cultural Rituals}

This topic includes four sub-themes: showing respect to the elderly, respecting an older brother, showing respect to an older sister, and typical rituals such as removing one's shoes before entering the home. The participants' responses referred to Turkish views on embracing cultural practices, such as the need to kiss the hands of older adults and to remove shoes before entering homes. Female Saudi viewers are interested in such cultural behaviors because they indicate how Turkish people are similar to Saudis.

\subsubsection{Wedding Rituals}

Saudi females thought that wedding rituals were one of the most positive and exciting aspects of TDs.

For example, one participant said, The exciting thing about Turkish people is their wedding culture'.

Wedding customs are distinctive and range from dealing with marriage contracts to wearing traditional clothes and dancing. The participants likely enjoy watching Turkish characters who, after getting married, display the agreement. As part of this custom, the bride is supposed to tread on the groom's foot. In that situation, the witnesses (friends) start clapping to encourage others (family and guests) to clap and start dancing.

As P3 stated, I love the bride with a big smile who raises her hands to show people her marriage contract.

Regarding clothing, Saudi women referred to traditional outfits worn before wedding ceremonies at small parties limited to family members. They had witnessed the bride covering her face with a red veil, a tradition in Turkish culture.

\subsubsection{Religious Rituals}

According to the participants, religious rituals had two sub-themes: funeral prayers and the commitment of the elderly to upholding religious duties. In terms of funeral prayers, the participants referred to funerals or death rituals presented in TDs as positive from a spiritual perspective.

For instance, P3 said, When Hussein died, his family came and cried; women were in hijab.

The reference to the presence of the hijab in TDs may indicate that the participants believe that it reflects their own Islamic identity, even if there were no specific scenes that highlighted the use of the hijab. While the hijab might be rare in some Turkey areas, Saudi women are widely worn in their everyday lives. Hence, it is assumed that the audience can identify the nationality of people in dramas from watching scenes where women wear the hijab, which in turn serves as a representative index and reflects the geographical location of theaters.

The respondents noted the commitment of older adults to religious duties. This may indicate that the participants enjoy observing the ritualistic habits of older adults who have religious obligations, such as praying, wearing the hijab, giving praise, and seeking forgiveness, even if such religious scenes are often minimal and brief. Religious rituals are widespread in everyday life in Saudi society, and praying in a mosque is common. In Saudi dramas, praying is a fundamental activity that is not limited to a particular age group.

\subsubsection{Food}

Turkish food was also considered to be a positive aspect of Turkish drama. This topic features four sub-elements: Turkish breakfasts, tea, desserts, and lunches. Most of the participants loved Turkish food, and representations of it specifically related to Turkey's cultural and social lifestyle. The participants loved to watch TDs simply to observe unusual food being consumed and pleasure being found in it.

P8 said, 'I want to eat kebab after seeing Turkish actors eat one in the show. 
It can be considered that participants like Turkish food because Turkish food and Arabic are similar.

\subsubsection{Fashion}

According to William (2013: 3), the dress is the key feature, which rapidly and continually changes in style. Fashion changes behaviors. The participants' responses indicate that fashion plays a vital role in TDs, with many regarding it as likely being the main feature of the shows.

This is also evident from the statement of $\mathrm{P} 5$, who said, I prefer to watch the Turkish soaps because the actors and actresses wear beautiful clothes and have luxurious accessories. It is simple, and sometimes it becomes indecent, but it is all still so attractive.

However, fashion in TDs is not exclusively focused on modern clothes. Traditional fashion is also portrayed, especially in historical soaps. Participants primarily appeared more interested in historical fashion than the modern one in such mediated storylines, which feature long dresses, jewelry, and unique hairstyles.

For instance, P1 stated, I love the dresses in Hareem Al-Sultan. They were very different, luxurious, and majestic ... the colors of the dresses, the hairstyles, the places, everything in that soap inspires me to identify with people's lives during that time. Some participants thought that one of the most positive elements of TDs was that traditional clothing was worn, particularly in soaps centered on sophisticated urban people living in small villages.

\subsection{Negative Impacts}

The participants considered some themes in TDs to be negative, in the sense that they could undermine Saudi socio-cultural values. Several studies have confirmed that exposure to TDs negatively influences (Al-Dulaimi \& Hussain, 2016; Iqbal, 2018; Snoussi, 2016). Figure 2 summarises such negative impacts in three significant categories: legal violations, ethical issues, and secularism. These categories have been further divided into the sub-categories of corruption, crime, scenes featuring sex talk, the consumption of alcohol, and the depiction of religious practices as being limited to the elderly.

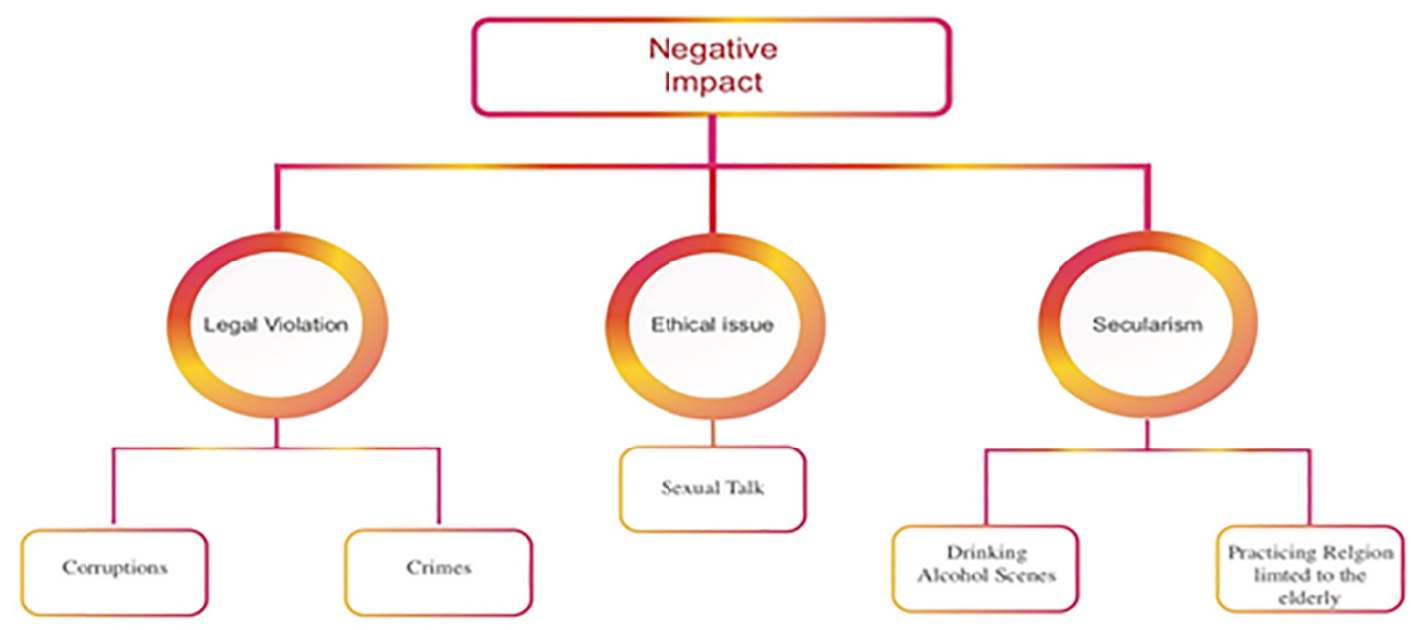

Figure 2. Negative themes, based on the responses of female Saudi participants

\subsubsection{Legal Violations}

TDs include various depictions of legal violations, shown within different contexts, with individuals carrying out crimes to protect themselves or escape punishment. The actions depicted in the scenes are shown as being acceptable ways to secure great opportunities. Through watching scenes that contain depictions of legal violations, criminals might find rationales for committing crimes. Turkish dramas have depicted crimes of revenge that went unpunished; instead, the criminals might establish a new life after getting their revenge. Perhaps, some audience may justify their desire to commit crimes of revenge based on the content of dramas. 
This theme includes two sub-themes: corruption and crime. Corruption is presented in the form of bribery and the manipulation of evidence. For example, TDs show people manipulating evidence to mislead a court, leading to the imprisonment of an innocent party instead of the real criminal, who is part of a wealthy family. Sometimes, corrupt characters are police officers who hide the truth and receive monetary bribes.

According to the participants, TDs often feature crimes that relate to gang membership or forms of bullying.

This shows the dark side of these dramas, where different crimes are expected compared to the real world (Al-Gazawi 2008). TDs sometimes represent the police, suggesting that gangsters and criminals have no respect for law or order and the police force itself. They are the dominant power. Hence, dramas often feature several layers of conspiracy, possibly in the characters' workplace or even in the street where they live.

The corrupt policemen shown in TDs suggest the idea of the police being a 'thin blue line' between anarchy and civilization (Hall et al., 2013; Lasley, 2012). Lauchs et al. (2011), for instance, state that police officers who engage in corrupt practices do so for a variety of reasons, and this results in the taking of bribes or the concealment of evidence. Saudi dramas, in comparison, are more ethical and often portray legal authorities as a source of help or wisdom. However, (critical) social conditions are represented in Saudi dramas through satirical expression.

As a result of how police officers are portrayed in Saudi dramas, Saudi audiences might somehow believe that Saudi police are not corrupt. Usually, Saudi police officers are comedically presented in dramas attempting to capture criminals after receiving the bribe.

\subsubsection{Ethical Issues}

The participants identified sex talk as a significant ethical issue that deviated from their own cultural, social, and religious perspectives. They assumed that TDs were using 'improper' sexual words either used on the street or by lower-class people. However, some characters who appear to be from the upper class also use such 'bad or vulgar' words incredibly when angry. In addition, TDs sometimes feature verbal or explicit sexual interactions between men and women, in what scholars could consider a brave and confident move.

P1 said Turkish dramas present bold scenes, especially scenes of lovemaking, and sometimes they use very negative words that have more of an impact than sexual conduct itself.

The participants tended to regard sex talk, as portrayed in TDs, negatively. This is consistent with other studies, such as those by Cipan (2014) and Yigit (2013) that pointed this out as being a particular drawback of TDs, especially for Arab audiences. For Saudi audiences, TDs may alternatively flout taboos or promote anti-Saudi values. Nonetheless, this does not appear to stop watching such programs. For instance, TDs may depict conversations about sensitive women's issues, such as virginity, or women living alone, which is still not considered acceptable in contemporary Saudi society. Extensive viewing of Turkish dramas, one could argue, might eventually assist in eroding such otherwise taboo subjects and help modify Saudi societal norms in line with cultivation theory. Notably, heavy viewers who are consistently exposed to TD over time will be influenced and identify with the characters more than viewers who have less exposure (Gerbner et al., 1986; Mosharafa, 2015; Williams, 2009).

\subsubsection{Secularism}

According to the participants, TDs show aspects of Islamic culture, such as the voice of Azan, even though Turkey remains a secular country, which broadly means that religious practices are separate from general society (Aljammazi \& Asli, 2017; Genc, 2018; Tombus \& Aygenc, 2017). Furthermore, representations of alcohol consumption are increasingly being featured in Turkish soap operas. These soaps can present alcohol consumption as a regular habit and behavior, with people needing alcohol to enjoy life or to help dampen unhappy feelings.

This is evident from the response of $\mathrm{P} 7$, aged 32, who said Turkish people are heavy drinkers because, in every soap, they drink alcohol. I thought that they would not drink in the story of Hareem Al-Sultan because it was a historical and religious story, but still, they drank. Turkish people love to drink a lot.

It is commonly known that Turkey is a secular country, which means that alcohol use is considered primarily from a social perspective rather than from a religious one. In contrast, alcohol is still prohibited and strictly forbidden in Saudi Arabia, despite recent changes. Another indication of Turkey's status as a secular country, from the perspective of female Saudi participants, was how TDs, in general, restrict religious activities to address the elderly. Participants observed that only elderly Turkish characters behaved like 'ordinary' Saudi Muslims in praying, wearing hijab, and rejecting alcohol. 


\subsection{Neutral Impacts}

Issues that had a neutral impact formed a distinct category in the participants' opinions of TDs. Some participants considered TDs to be neither positive nor negative. This means that the participants had either indifferent, conflicting, or ambivalent beliefs or attitudes regarding specific issues represented, such as relationships, gender roles, ethical matters, and secularism. As a result, some Saudi women feel a sense of imbalance or hold an uncaring attitude towards such dramas. For instance, some Saudi women might adapt their views of friendship between men and women and justify their perspectives as a form of cultural openness, particularly in light of social changes in Saudi society today. Figure 4 illustrates the four main themes of this more ambiguous or a grey area of cross-cultural engagement.

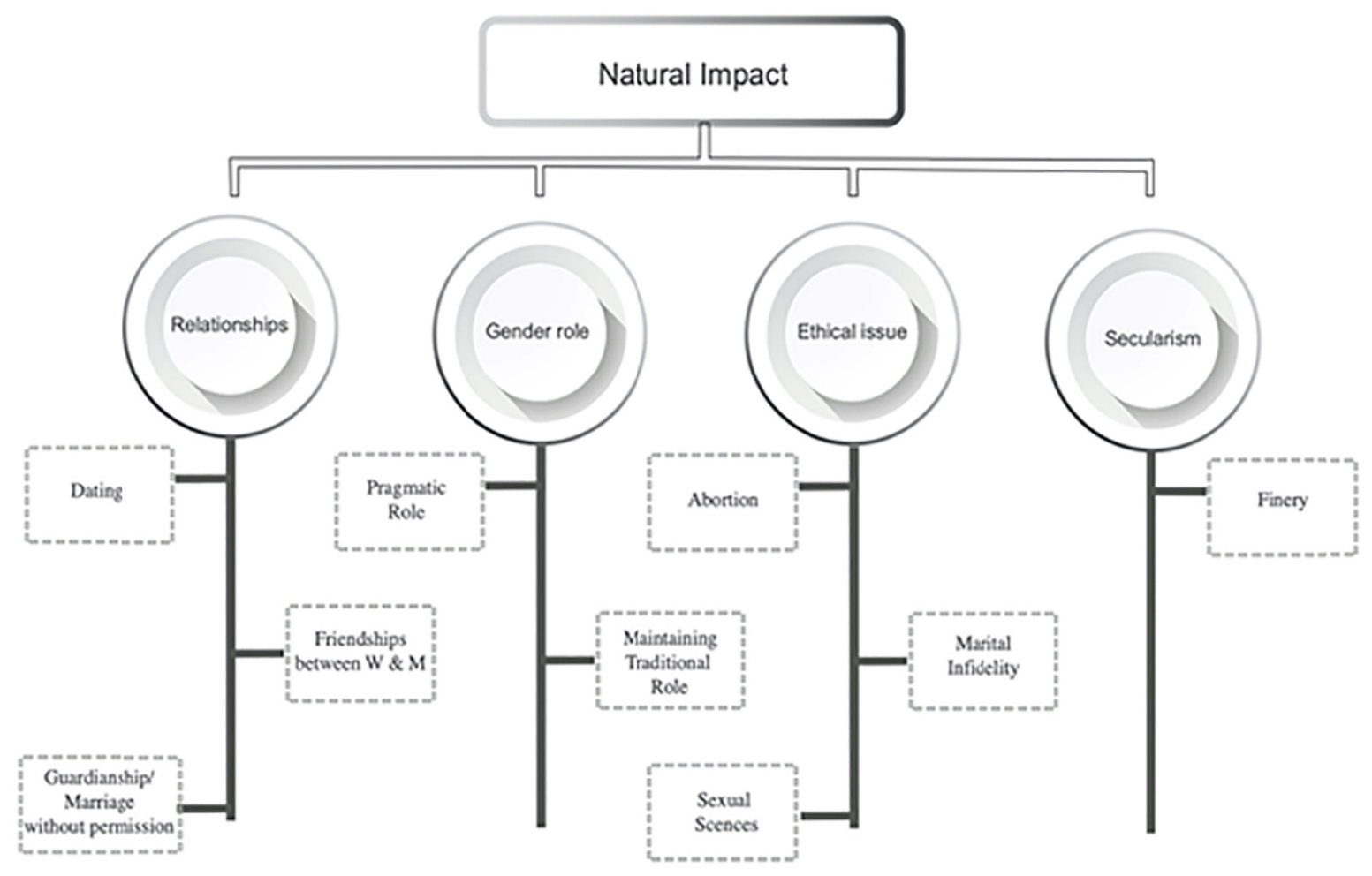

Figure 3. Main themes for neutral impacts

\subsubsection{Relationships}

Responses revealed that romance, passion, and love are the main aspects and goals of relationships between women and men portrayed in TDs. Consequently, this theme addresses three specific elements: dating, the friendship between women and men, and guardianship focused on the taboo of getting married without permission. In Islam, dating is forbidden (Kalim, 2019), but Saudi women have different opinions on its value within developing relationships. For example, a few of the sample identified dating as an inappropriate activity from an Arabic cultural perspective. Nonetheless, they accepted the idea of dating at least on screen and adapted it while providing a verbal rationale for such paradoxical behavior.

For instance, $\mathrm{P} 3$ said that sometimes a man could meet a woman before establishing a proper relationship to get to know each other well; it is ok. While other participants, given religious and social norms, rejected the concept of dating altogether.

About friendships with people of the opposite sex, some participants also rejected such a proposition.

For example, P1 said, 'The relationship between men and women should lead to marriage. We are Muslims, and relationships must be within the context of marriage. 
Given cultural and social factors in Saudi Muslim society, the idea of friendship between the opposite gender is rejected, and some participants believed that TDs could at least potentially destroy their cultural and religious identities.

P4 stated I think watched Turkish dramas are harmful to the cultural values of young Saudi girls, especially their religious beliefs.

This aligns with the findings of several studies (Aslam \& Faiz Ullah, 2015; Mutlu, 2013; Zafer et al., 2017). However, some participants thought the opposite and justified their attitudes by affirming that friendship is a healthy form of human relationship. Regarding marriage without permission, participants might be expected to reject the concept outright, given strict Saudi cultural and religious values that emphasized arranged marriages approved by guardians. Other participants, however, dealt with the idea of marriage without permission and argued that women should be able to choose their husbands.

P6 asserted that adult Saudi women could decide without their fathers or brothers.

\subsubsection{Gender Roles}

The participants appeared to have a heightened level of disagreement around gender roles in TDs, as illustrated by the sub-themes. They differentiated between functional and traditional roles in modern Saudi society. Some participants minimized this inherent conflict by accepting the role of 'modern' women, as highlighted in TDs. Other participants seemed to agree that women could have multiple functions, such as being a wife, a mother, and a lover.

\subsubsection{Ethical Issues}

TDs can actively feature sensitive issues that relate to women in particular. This theme covers three crucial and sensitive issues: abortion, marital Infidelity, and explicit sexual scenes. Most participants were expected to reject abortion and regard it as a negative aspect of TDs.

For example, P1, aged 51, I think one negative aspect of such dramas has a child without getting married. Turkish dramas sometimes show a relationship between a young girl and her boyfriend as a mix of emotions and love, and it is assumed that a girl might be adventurous by fighting for love and ignoring social norms. Then, when the love affair ends, she has had a child without getting married.

Marital Infidelity, or cheating on one's spouse, is carried out by both men and women. Most participants were expected to reject this practice, as represented in TDs, because it seems unethical.

For example, P1 said, I do not know why Turkish dramas show several forms of Infidelity - the Turkish people even reject it'. Of course, in the real world, people try to hide Infidelity, but seeing it in dramas may lead the audience to engage with a taboo subject in one way or another. P5 pointed out an example, stating that, Infidelity is common in Turkish dramas, in terms of both husband and wives. Many studies have confirmed this, such as Al-Hamdani (2014) and Zhag and Sakry (2019).

However, a few participants accepted marital Infidelity in TDs, justifying by saying that TDs tease out complex and challenging emotional issues.

As P6 noted, I know a woman and man who had a forbidden relationship, but if I were her, I would choose to love Muhanad, not her husband, Adnan, who is old and ugly compared to Muhanad, a nice and kind man. People have conflicting emotional concerns regarding this topic, which is likely to be reduced by how they provide a rationale that allows them to adapt to the prospect of marital Infidelity. In other words, audiences can engage in vicarious involvement by becoming immersed in an identification mechanism; it is one of the most crucial methods of interaction a viewer may create with an actual or imagined identity (Brown, 2020; Brown, 2015). Yet, concerning explicit or non-explicit sexual scenes, most participants rejected outright such behavior and actions because of their socio-cultural beliefs. However, a few appeared to alter their attitudes to adapt their stance to their first-hand exposure to sexual scenes in TDs.

\subsubsection{Secularism}

Based on the participants' observations of TDs, Turkey, as already mentioned, is perceived and recognized as a secular country - at least from the perspective of Saudi society. In terms of cognitive dissonance, most participants felt conflicted between what they believed, strictly moral philosophy, and what they witnessed in such fictional TDs. Consequently, they rejected the portrayal of flippant costumes and finery, according to their social norms. Several studies have supported this evaluation (Al-Gazawi, 2008; Al-Masry, 2013; Hamesy, 2014). Nevertheless, a few participants accepted the celebration of finery worn by women as a type of openness, or even liberation, which can more recently be found in contemporary Saudi society. 
Perhaps, participants adapted to some of the unacceptable behavior in dramas simply because they admired the Turkish actors. Recently, the trend may have depicted complex characters with both positive and negative features or simply as heroes and anti-heroes. As they identify with the characters, Saudi viewers might be empathetic to actors; viewers might attempt to rationalize evil behaviors such as murder. Cognitively, viewers could replace their feelings of guilt that conflict with their social norms and cultural values with alternative and more acceptable feelings of pleasure. They consider such actors as heroes. This illustrates how media may present some actors in a positive light outwardly, at least, while inwardly, their intentions might be criminal and very negative. In these situations, actors could be considered morally complex characters. For example, from famous Western examples, Breaking Bad (2008-2013), Dexter (2006-2013), and Money Heist (2017-2019); all of which represented the main characters at first as good and virtuous people who helped others, but retained some fatal flaw, as in all great dramas from Shakespeare to the present. Characters often become corrupt and commit different forms of crimes.

Conceptually, soap operas or films might represent anti-heroes as brave, powerful, destroying, and challengers of society; simultaneously, the characters strive to protect their family members and are often good emotional husbands and kind fathers. Surprisingly, those characters were likable by some viewers who could engage with them, especially if they were attractive. Audiences may greatly admire them based on the paradox between the two sides of their personality, recalling the antihero who opposes the orthodox hero (Tokgoz, 2016). Audiences can infer the following action or step of the hero's journey (Van Eeden Harrison, 2017; Mahoney, 2010), typically righteous and moral. However, with an anti-hero, the situation is different. Audiences may find it difficult to predict the following action because an anti-hero is a complex character whose conduct is not consistently good or bad. As a result, the line between hero and the anti-hero is incredibly porous and thin; it might be constituted as a grey area, based on a character's actions, especially if the anti-hero changes to become a full-fledged hero end of the story. Tobin (2000), focusing on Greek mythology or Shakespearean writings, stated that a tragic hero's (anti-hero) demise could be traced to the point of time in which they chose to follow a negative trajectory rather than use it as an opportunity for transformation and change. In other words, good people with good values could make errors or tragic mistakes (Devi, 2014; Raspa, 2016); they would even face a conflict when they finally recognize their mistakes before dying.

Devi (2014:3) defined the so-called tragic flaw applied to Shakespearean drama, particularly when he said a tragic flaw is a literary term that refers to a personality trait of the protagonist that leads to their downfall due to the personal defect of character. In other words, the hero who made a catastrophic error should be punished, and audiences would learn from their tragedy. Kriegel (2010: 138) also supported the notion that audiences could benefit from the mistakes of others when pronouncing. Shakespeare provides his heroine, using his hero, with a mentor - in the person of Friar Laurence - one with the opportunity to offer valuable moral lessons.

Indeed, audiences can connect and identify with a 'fatal flaw' of a hero. Despite their many differences, Turkish dramas might also allude to such fatal flaws through the depiction of complex characters that leads audiences to face a dilemma in classifying characters as either simply positive or negative. For example, 'The Magnificent Century portrayed one of the main characters, 'Ibrahim Bash,' the grand minister of the Ottomans Empire, as a powerful and brave man (Jenkins, 2014). However, when he made a tragic error, his punishment by the royal order of King Soliman was death. TD could help educate audiences, drawing on the Shakespearean aesthetic and approach to learning from heroes' fatal errors, including anti-heroes and their suspect actions. In essence, emotional responses of the audiences - even so-called 'low brow' Turkish soap operas - to the attitudes, motives, and emotional reactions of the characters, can be construed as a result of engaging with emotional and spiritual judgemental mechanisms.

Nonetheless, Zillmann (2000) argued that such villains remain unacceptable at all levels, simply based on their wicked behavior ethically and socially. The intensity that results in audience responses - much less scholarly observation - between different forms and embodiments of characters can, in turn, lead to feelings of both pleasure and satisfaction (Raney and Janicke, 2015). Perhaps, Turkish dramas following a different but related religious ethic combine aspects of heroes and anti-heroes across more popular and resonant soap operas, films, and movies, all freely available through Netflix.

\section{Discussion}

It was especially obvious in researching the topic that Saudi women were conflicted when watching TDs. Therefore, to assist in understanding such varying responses, they were divided into three schematic groups, drawing on their differing responses and attitudes. The first group experienced positive impacts across three prescribed attributes: relationships, attractiveness, and culture and tradition. Echoing the findings of others (Qudah \& Tahat, 2013; Ibrahim, 2014), TDs presented several positives for audiences to embrace, such as their portrayal 
of fashion, emotion-laden romance, and the attractiveness of both the natural world and engaging performers and actors.

The second group generally had a negative attitude towards TDs. Negative factors were divided into four broad themes: legal violations, relationships, ethical issues, and secularism. In line with previous findings (Al-Hamadani, 2014; Al-Masry, 2013; Hamesy, 2014; Al-Ali \& Makki, 2018), exposure to TDs explicitly spread some negative attributes' issues (such as the consumption of alcohol, sex talk, corruption, secularism, and crime). But more needs to be done to test and evaluate such broad-based findings.

The final group (participants with neutral responses) was characterized across four themes: relationships, gender roles, ethical issues, and secularism. Meanwhile, and most importantly, this study also investigated the evolving ambiguous and a grey area around the impact of TDs on audiences. The findings indicate that participants who had different responses to TDs face inherent conflicts, alternating between what they believe within the context of local and national social norms and what they are exposed to when watching foreign soaps, such as TDs. This finding aligns with the concept proposed in Cognitive Dissonance Theory (Festinger et al., 1956). Different participants considered the theme of relationships and their representation on the Turkish soap operas to be either negative, positive, or neutral. This indicates further that there is a level of active audience participation when receiving messages through a mediated platform, such as TDs (Buckingham, 2007; Livingstone, 2009; Srinivas, 2002). The overarching concept of media competency and literacy supports the notion that audiences actively interpret, analyze and make judgments about perceived media messages (Grace, 1990). But as Brereton (2019) rightly affirmed, the primary focus must be the idea of what people do with media, their level of interpretation of media, and their responsiveness to media texts.

The main limitation of this study is that the objective population was made up of a small sample of Saudi females who had exposure to Turkish dramas. Consequently, the present results cannot be used as a straightforward generalization for the entire Saudi female population due to the small sample used. Further large-scale qualitative and quantitative studies are needed to corroborate and deepen this initial pilot case study.

\section{Conclusion}

There are two approaches that audiences might use as they interpret the behaviors and messages of heroes or anti-heroes - first, recalling Shakespearian classic school of engagement, which suggests that protagonists who commit tragic errors should be punished regardless of their external or internal causes. Secondly, the viewpoint from a contemporary and secular school of thought could be that audiences might justify the behaviors of negative characters and adjust their interpretation based on internal or external causes. Thus, consumers, or viewers, may understand and evaluate different values, via TDs, through perceived diversity of meanings within the content. Future studies in this area need to focus on the importance of socio-cultural realities grounding on ethical values as they affect Saudi women's perception and value proposition.

\section{References}

Ainou. (2019). Trends of university students toward Turkish series, which are included in the light of the variable housing: A field study on a sample of Saida university students. The Algerian Journal of Mass Media and Public Opinion, 2(2), 205-229.

Al-Ali, F., \& Alshammri, A. M. (2018). Usages of the Youth in the Emirati Society for the Dubbed Turkish Series on the Arab Satellite Channels and the Satisfactions Achieved. AL-Bahith AL-A'alami, 10(41).

Algan, E. (2005). The role of Turkish local radio in the construction of a youth community. Radio Journal: International Studies in Broadcast \& Audio Media, 3(2), 75-92. https://doi.org/10.1386/rajo.3.2.75/1

Aljammazi, A., \& Asil, H. (2017). The Influence of Turkish TV Dramas on Saudi Consumers’ Perceptions, Attitudes and Purchase Intentions toward Turkish Products. International Journal of Academic Research in Business and Social Sciences, 7(1), 206-224. https://doi.org/10.6007/IJARBSS/v7-i1/2600

Al-Masry. (2013). The impact of dubbed soap operas of the Arab channel satellites on the University Youth Palestine's Values. Islamic Journal University for human research, 21(2), 363-395.

Alsaffar, A. H. (2012). Attitudes of Kuwaiti University Students towards the Drama Series in Arab TVs. Doctoral dissertation, Master thesis. Faculty of Media, Middle East University.

Aslam, A. A., \& Faiz Ullah, M. (2015). Socio-Ethical Impact of Turkish Dramas on Educated Females of Gujranwala-Pakistan'. Journal of Humanities And Social Science, 125-131. 
Balli, F., Balli, H. O., \& Cebeci, K. (2013). Impacts of exported Turkish soap operas and visa-free entry on $\begin{array}{llll}\text { inbound to to } & \text { Turism }\end{array}$ https://doi.org/10.1016/j.tourman.2013.01.013

Becker. (1987). Discovering Mass Communication. 2nd ed. Scott: Foresman \& Company.

Berg, M. (2017). The importance of cultural proximity in the success of Turkish dramas in Qatar. International Journal of Communication, 11, 16.

Bhutto. (2019). The days of American culture dominance are over interviewed by Steve Inskeep. NPR. Retrieved from

https://www.npr.org/2019/09/27/764946119/the-days-of-american-culture-dominance-are-over-author-says

Braun, V., \& Clarke, V. (2006). Using thematic analysis in psychology. Qualitative research in psychology, 3(2), 77-101. https://doi.org/10.1191/1478088706qp063oa

Brereton, P. (2018). Environmental literacy and new digital audiences. Routledge. https://doi.org/10.4324/9781315169682

Brown, W. J. (2015). Examining four processes of audience involvement with media personae: Transportation, parasocial interaction, identification, and worship. Communication Theory, 25(3), 259-283. https://doi.org/10.1111/comt.12053

Brown. (2020). Identification. The International Encyclopedia of Media Psychology, 1-8. https://doi.org/10.1002/9781119011071.iemp0126

Buckingham, D. (2007). Digital Media Literacies: rethinking media education in the age of the Internet. Research in comparative and international education, 2(1), 43-55. https://doi.org/10.2304/rcie.2007.2.1.43

Cipan. (2014). Between acceptance and resetences: a case study of Turkish soap operas in Egypt. Unpublished MA thesis. Istanbul Sehir University.

Çorbaci, K., \& Çetinsoz, B. C. (2008). A Study of Arab Tourists' Choice and Revisiting Intentions for Holiday in Mersin, Turkey Destination. HOSTEUR, 7(2).

DURMUS,, H. E. (2016). The Representation of Turkey Through Narrative Framing-Saudi Arabian and Turkish Newspapers' Coverage of the Arabic Dubbed Turkish Series Noor. Moment Dergi, 3(2), 483-507. https://doi.org/10.17572/mj2016.2.483507

Elouardaoui, O. (2013). Spanish-Language Telenovelas and Turkish Soap Operas on Arab Television: Cultural Adaptations and Social Effects. University of California, Santa Barbara.

Festinger, L., Riecken, H. W., \& Schachter, S. (1956). When Prophecy Fails (Min-neapolis). https://doi.org/10.1037/10030-000

Fish, S. E. (1980). Is there a text in this class? The authority of interpretive communities. Harvard University Press.

Genc, M. F. (2018). Values education or religious education? An alternative view of religious education in the secular age, the case of Turkey. Education Sciences, 8(4), 220. https://doi.org/10.3390/educsci8040220

Georgiou, M. (2012). Watching soap opera in the diaspora: cultural proximity or critical proximity? Ethnic and Racial Studies, 35(5), 868-887. https://doi.org/10.1080/01419870.2011.628040

Gerbner, G., Gross, L., Morgan, M., \& Signorielli, N. (1986). Living with television: The dynamics of the cultivation process. In J. Bryant \& D. Zillman (Eds.), Perspectives on media effects (pp. 17-40). Hilldale, NJ: Lawrence Erlbaum Associates.

Güneş, H. S. (2016). Audience reception of teen TV dramas: experience of romance and pleasure (Doctoral dissertation, Bilkent University).

Hall, S., Critcher, C., Jefferson, T., Clarke, J., \& Roberts, B. (2013). Policing the crisis: Mugging, the state and law and order. Macmillan International Higher Education. https://doi.org/10.1007/978-1-137-00721-6

Hamasaeed, N. H. (2012). The impact of commercial global television on cultural change and identity formation. A study of Kurdish women and the Turkish soap opera'Noor' (Doctoral dissertation, University of Bradford).

Hamed. (2017). The impact of viewing Turkish drama soap operas through the Arab channels on the Yemeni female students' values. Al-Andalus Journal for Human Science and Sociology, 16(17), 81-181. 
Hamesy. (2014). The Dubbed Turkish Dramas and The Impact of them on the Youth. Unpublished MA thesis. The University of Al-wadi.

Ibrahim. (2014). The value content of the Turkish drama and its effect on the cultural, social component of the Sudanese society (2008 - 2010). Unpublished MA thesis. The University of Al-Jazeera.

Iqbal, M. (2018). Effects of Turkish dramas on university students: A survey of Pakistani Universities. Journal of Mass Communication \& Journalism, 8(5). https://doi.org/10.4172/2165-7912.1000394

Jenkins. (2014). Ibrahim Pasha, Grand Vizir of Suleiman the Magnificent. Cloubia studies in the social science studies in history, economic and public law, 115. Published PhD thesis: Columbia University.

Kalim. (2019). Dating in Islam.

Kriegel, J. (2010). A case against natural magic: Shakespeare's Friar Laurence as Romeo and Juliet's near-tragic hero. Logos: A Journal of Catholic Thought and Culture, 13(1), 132-145. https://doi.org/10.1353/log.0.0059

Lasley, J. (2012). Los Angeles police department meltdown: The fall of the professional-reform model of policing. CRC Press. https://doi.org/10.1201/b12530

Lauchs, M., Keast, R., \& Le, V. (2011). The motivation and structure of corrupt police networks: theorising the dark side of the'thin blue line'. In 15th Annual Conference of the International Research Society for Public Management.

Livingstone, S. (2009). On the mediation of everything: ICA presidential address 2008. Journal of communication, 59(1), 1-18. https://doi.org/10.1111/j.1460-2466.2008.01401.x

Lorusso, A. M. (2015). Cultural semiotics. Palgrave Macmillan. https://doi.org/10.1057/9781137546999

Mahoney, K. P. (2010). The Ultimate Fan's Guide to Avatar: James Cameron's Epic Movie. Punked Books.

Megdad. (2015). The impact of dubbed Turkish drama on the students of media colleges at the Qaza sector. Conference Qaza University, 1-17.

Mercer, J., \& Shingler, M. (2013). Melodrama: Genre, style and sensibility. Columbia University Press.

Mosharafa, E. (2015). All you need to know about: The cultivation theory.

Mutlu, M. M. (2013). Women and Tradition in Turkish Television Culture: The Modern day representations of Rape and Pre-marital sexuality (Doctoral dissertation, Uppsala University).

Qudah, M., \& Tahat, Z. (2013). Dubbed series and their possible effects on adolescents. International Journal of Scientific and Technology Research, 2(2), 38-49.

Raspa, A. (2016). Macbeth's Imagination as Fatal Flaw. In Shakespeare the Renaissance Humanist (pp. 77-94). Palgrave Macmillan, New York. https://doi.org/10.1057/9781137580160_4

Salih, N. B. (2017). A Dubbed Turkish Drama and their Effects of the Behavior of Algerian Women A Survey Study of a Sample of Women-The City of Mesila is a Model. AL-Bahith AL-A'alami, 9(37).

Shahbaz Aslam, D., Ali, A., Ullah, F., \& Munawar, M. (2015). Socio-Ethical Impact of Turkish Dramas on Educated Females of Gujranwala-Pakistan.

Snoussi. (2016). Turkish drama and its effects in Arabic youth: Semiotic study. Journal of Arab States Broadcasting Union (ASBU), 1, 102.

Soheli. (2011). The Values in the Turkish dramas- A Case Study on the Black Money Soaps. Algerian Scientific Journal Platform, 21(42), 608-634.

Srinivas, L. (2002). The active audience: spectatorship, social relations and the experience of cinema in India. Media, Culture \& Society, 24(2), 155-173. https://doi.org/10.1177/016344370202400201

Talha. (2018). The cultural impact of the Turkish serials on the students of Sana university: A survey study. Algerian Journal of Research and Studies, 4, 46-62.

Temraz. (2016). The impact of dubbed series dramas on the student's universities from the Gaza sector. The University of Palestine.

Tobin. (2000). How to write hight structure, hight concept movies. Philadelphia: Xlibris Corp.

Tokgöz, Y. (2016). The rise of the anti-hero: pushing network boundaries in the contemporary US television. 
Tombuş, H. E., \& Aygenç, B. (2017). (Post-) Kemalist Secularism in Turkey. Journal of Balkan and Near Eastern Studies, 19(1), 70-85. https://doi.org/10.1080/19448953.2016.1201995

Toul. (2020). The influence of Turkish series presented on Arab satellite channels on changing the style furniture in Algerian houses. Afaq Science Journal, 17(5), 142-151.

van Eeden Harrison, J. (2017). Beyond the biopic an exploration into the nature of biography through the medium of film (Doctoral dissertation).

Williams, D. (2006). Virtual cultivation: Online worlds, offline perceptions. Journal of communication, 56(1), 69-87. https://doi.org/10.1111/j.1460-2466.2006.00004.x

Williams. (2013). The rise of Turkish soap power. BBC News. Retrieved from https://www.bbc.com/news/magazine-22282563

Yanardağoğlu, E., \& Karam, I. N. (2013). The fever that hit Arab satellite television: audience perceptions of Turkish TV series. Identities, 20(5), 561-579. https://doi.org/10.1080/1070289X.2013.823089

Yigit, A. (2013). Turkish drama in the Middle East: Secularism and cultural influence. IEMed: Mediterranean yearbook.

Zafar, A., Arafat, Y., \& Sial, N. R. (2017). Effects Of Turkish Soap Operas On The Female Youth Of Pakistan. The Women-Annual Research Journal of Gender Studies, 9(9).

Zhag, \& Sakry. (2019). The impact of Turkish drama on the changing the Algerian women values. Unpublished MA thesis.

Zillmann. (2000). Basal morality in drama appreciation. In I. Bondebjerg (Ed.), Moving images, culture and the mind (pp. 53-63). Luton: Luton University Press.

\section{Copyrights}

Copyright for this article is retained by the author(s), with first publication rights granted to the journal.

This is an open-access article distributed under the terms and conditions of the Creative Commons Attribution license (http://creativecommons.org/licenses/by/4.0/). 